\title{
LA REFLEXIÓN TRADUCTOLÓGICA: UNA REVISIÓN DIACRÓNICA (I)
}

\author{
Isabel Hervás Jávega
}

\begin{abstract}
The paper deals with the topic of Translation Studies History from Roman Times up to the middle of the 20th century, when Translation Studies started to be considered as an independent field of research. It goes through Roma, Medieval Times (touching upon biblical translations and its social, political and religious implications, as well as Arabic translations and its consequences on the general panorama of the European culture), Renaissance, Clasicism and Romanticism. It focuses its attention on how the main questions of translations and translators ("what to translate"; "why to translate"; "how to translate"; and finally "to whom") were answered through the History of Translation. Across the exposition it appears clearly that those answers only led to dead-locks like literal translations versus free translations; or translations that bear in mind the reader versus translations that do not, leaving no possibility to jump out those useless dichotomies.
\end{abstract}

A lo largo de la Historia de la Traducción los traductores no sólo han desempeñado su labor con mayor o menor fortuna, sino que también han reflexionado sobre ella. Varias son las cuestiones que recurrentemente se han ido planteando, aunque no siempre todas ellas han tenido igual importancia ni en todo momento se han resuelto de la misma manera. Las preocupaciones que básicamente han motivado la reflexión teórica sobre el hecho traductológico son las siguientes: por qué, qué, cómo y para quién traducir. En este artículo ofreceremos una breve revisión diacrónica de cuál ha sido el foco de interés en cada época histórica y la respuesta que en esa misma época se le dio.

\section{La Roma Clásica}

Se podría afirmar que en occidente la Historia de la Traducción comienza con Roma, al menos en lo que respecta al papel que las traducciones jugaban y a la posición de prestigio que se les otorgaba ${ }^{1}$. Cicerón, y cincuenta años más tarde Horacio, son los mejores exponentes de la tradición traductológica latina. Para ellos la traducción era una más de las

\footnotetext{
${ }^{1}$ S. Bassnet-McGuire, Translation Studies (London \& New York 1980), 43-45.
} 
funciones que un poeta debía cumplir para con su entorno, que a grandes rasgos era adquirir sabiduría para más tarde difundirla a través del arte de componer poesía. Los romanos se sentían los continuadores de los modelos literarios heredados de Grecia, cuya lengua gozaba de la consideración de ser el medio de transmisión cultural por excelencia, de manera que un romano culto podía leer sin grandes dificultades tanto el latín como el griego. Por tanto, un texto traducido era leído a través del texto original, y así los traductores romanos no se sentían constreñidos por la limitación de trasladar de una lengua a otra o bien un contenido textual o bien una forma textual para lectores monolingües. Por el contrario, se sentían con la relativa libertad de ejercitar su capacidad poética en la recreación del modelo que estaban intentando imitar y emular en un proceso de estilística comparada. En conexión con esta concepción está la misión del traductor como introductor de neologismos griegos con el fin de enriquecer la lengua latina, si bien Horacio advierte contra la inmoderación en tal hábito.

Por todo lo dicho se entenderá que, tanto para Cicerón como para Horacio, el arte de traducir consistiera en una juiciosa interpretación del texto original con el fin de producir un texto traducido basado en el principio de non verbum de verbo, sed sensum exprimere de $s e n s u^{2}$, es decir, traducir no palabra a palabra, sino figura a figura, traducir el sentido, y hacerlo así para que los lectores del texto de llegada lo entendiesen.

\section{La Biblia}

Unos años más tarde, pero ya en un mundo cristiano, san Jerónimo se mantiene en la misma tesis, aunque haciendo una capital salvedad: la Biblia. En respuesta a la acusación hecha por enemigos suyos de haber traducido -del griego al latín-intencionadamente mal una carta que el Papa san Epifanio había dirigido al obispo Juan de Jerusalén en el año 394, san Jerónimo se defiende diciendo que él no ha cambiado nada en el sentido de la carta, y añade: "Pues yo no sólo confieso, sino que abiertamente proclamo que en la traducción de los griegos, fuera de la Sagrada Escritura, donde hasta el orden de las palabras es un misterio, no expreso palabra por palabra, sino sentido por sentido"3 De esta manera declara sin ambages lo que de hecho ocurriría a lo largo de toda la Edad Media europea, a saber, que mientras que en los textos profanos se seguían criterios estilísticos en donde primaba el sentido, en el texto religioso el literalismo es lo que prevalece. Dicho de otra manera, san Jerónimo -que a mediados del siglo IV fue el encargado de traducir la más conocida versión en latín de la Biblia, la Vulgata- continúa los postulados latinos mientras no se desafíe el poder establecido, el de la Iglesia, que precisamente basa su autoridad en ser la única capacitada para interpretar la Biblia.

\footnotetext{
${ }^{2}$ Marco Tulio Cicerón, M. Tulli Ciceronis rethorica (Oxonii 1989)

${ }^{3}$ San Jerónimo, "LVII. Ad Pammachium de optimo genere interpretandi", Saint Jérôme: Lettres, III (París 1953), $55-$ 73
} 
En realidad, la historia de las traducciones bíblicas es como una historia de la cultura occidental en microcosmos, y ha sido hasta bien entrado el siglo XVII foco central de discusiones metodológicas. A nadie le resulta desconocido que en el revuelto panorama de la Europa del XVI la traducción de la Biblia se usó como arma política y dogmática en los conflictos de las emergentes naciones occidentales frente al centralista poder papal -aliado con la omnipresente dinastía española de los Austrias-, y en términos lingüísticos las luchas de poder se reflejaron en el arrinconamiento del latín como lengua de cultura frente a las distintas lenguas nacionales.

La primera traducción completa de la Biblia al francés se hizo en 1235, y la primera que se vertió al inglés -en el 735 Beda había traducido el Evangelio de San Juan al inglés antiguo- la realizó John Wycliffe entre 1380 y 1384 . Wycliffe era un teólogo británico que propugnaba que el ser humano era directamente responsable ante Dios y ante su Ley, lo que implicaba que debía tener garantizada la lectura de esa Ley, es decir, la Biblia en lengua vernácula (Bassnett-McGuire 1980, 46-47). Esta labor fue continuada por su discípulo John Purvey, quien revisó la edición de su maestro y le añadió un prólogo -compuesto alrededor de 1395- que antes de 1408 ya estaba en circulación. En este prólogo Purvey detalla los pasos que se deben dar para traducir, entre los cuales el principal es hacerlo en función de las frases (el sentido), y no sólo por las palabras: lo que se pretende es un texto inteligible para un hombre normal.

Por supuesto, tanto las copias de Wycliffe como las de Purvey fueron prohibidas, a pesar de lo cual se sabe que hasta 150 de éstas existían en 1408. En el siglo XVI una nueva y vigorosa variable entra en juego con la invención de la imprenta, que multiplica la capacidad de difusión de las obras escritas, entre ellas las distintas versiones bíblicas traducidas a las lenguas vérnaculas de los pujantes nacionalismos europeos. En 1482 se imprime en Bolonia el Pentateuco hebreo, y en 1488 aparece la Biblia hebrea completa. Erasmo publica en 1516 el primer Nuevo Testamento griego en Basilea, de donde saldría la versión alemana de Martín Lutero en 1522, que en 1534 completó con una del Antiguo Testamento también directamente traducida de la lengua original, en este caso el hebreo. No fue la única: en 1529 apareció la danesa, y una segunda versión en 1550; en sueco fueron igualmente dos, en los años 1526 y 1541; la checa se publicó entre 1579 y 1593. La siguiente versión inglesa que vio la luz fue la de William Tyndale en 1525, que tradujo directamente del griego, y para cuando fue quemado por hereje en 1536 ya había traducido parte del Antiguo Testamento del hebreo. Tyndale no fue el único en morir torturado por traducir las Sagradas Escrituras, ya que el peligro que esto suponía no detenía la imparable marea que sacudía Europa. España no fue una excepción y también a mediados del siglo XVI sale a la luz la llamada Biblia del Oso, la primera traducción al castellano de los textos sagrados. La hizo un monje sevillano perteneciente a la Orden de los Jerónimos de Santiponce, Casiodoro de la Reina, bajo la influencia de los aires de renovación que Erasmo había traído a la Iglesia católica. Casiodoro pudo escapar in extremis de la hoguera, aunque no así sus compañeros del convento de Santiponce. Grosso modo, las intenciones de los traductores bíblicos del XVI se podrían sintentizar en: 
- Clarificar errores de versiones previas, ya hubiesen sido producidos por deficientes manuscritos en las lenguas originales -hebreo y griego-, ya por incompentencia lingüística de los traductores.

- Producir un texto en lengua vernácula que fuese satisfactoriamente estético y asequible para el hombre normal.

- Aclarar los dogmas y así reducir el campo de acción en el que las Sagradas Escrituras eran interpretadas y representadas para el hombre normal como un metatexto.

Para Lutero el segundo punto era de capital importancia, junto con la relación que se establece entre estilo y significado. En su celebérrima Sendbrief vom Dolmetschen, datada en 1530, declara contundentemente que su intención al traducir el Nuevo Testamento al alemán ha sido hablar alemán y no latín o griego, añadiendo las palabras o expresiones necesarias de la lengua vernácula para la explicación del sentido del original ${ }^{4}$. No se puede olvidar que estos traductores renacentistas partían prácticamente de la nada, en cuanto que estaban traduciendo de unas lenguas secularmente literarias a otras en las que apenas si había producción escrita alguna: estaban creando las lenguas poéticas de las nuevas naciones. La fluidez y la inteligibilidad de los textos era un criterio esencial para ellos, pero igualmente lo era la precisión en la trasmisión del mensaje del texto original en una época en la que el cambio de un pronombre podía significar la muerte. En España, Fray Luis de León traduce el Cantar de los Cantares al castellano y en el prólogo de su versión declara que en la medida de lo posible ha intentado traducir palabra por palabra, seguida de una explicación de lo traducido en cada capítulo. De esta manera Fray Luis permanece en la esfera de la literalidad, aún haciendo la concesión de la glosa añadida para entender el sentido de lo traducido.

El proceso de las traducciones bíblicas no se detuvo, por supuesto, en el siglo XVI -de hecho, uno de los grandes teóricos contemporáneos de la Traductología, E.A. Nida, es un traductor bíblico- y sólo en inglés se podrían destacar las versiones de 1560 -conocida por el nombre de la Biblia de Ginebra-, o la de 1611 que el rey Jacobo Estuardo de Escocia -y que por ello se llama The King James Version- encargó a cincuenta eruditos. Hasta 1870 estuvo vigente en la Iglesia Anglicana, momento en el que se decidió su revisión, de donde salió la English Revised Version, publicada en 1885. Con posterioridad han seguido la American Revised Version de 1901, y en 1957 la Revised Standard Version, que son las traducciones norteamericanas de la Biblia.

No es éste el momento -ni ésa es mi intención- de hacer un exhaustivo recuento de todas las traducciones realizadas de la Biblia. Pero sí quisiera remarcar que, en mi opinión, merecería por sí misma un estudio exclusivo desde el punto de vista de la Traductología moderna. Constituye el hito más destacado en la historia de la traducción de textos por muchas razones: por cantidad de versiones hechas; por las implicaciones sociales, políticas

\footnotetext{
${ }^{4}$ M. Lutero, "Sendbrief vom Dolmetschen", Ausgewählte Schriften (Frankfurt 1983)
} 
y dogmáticas que ha tenido; por su trascendencia lingüística en la formación de las lenguas literarias, por la extensión en el tiempo de su vigencia como objeto deseable de traducción,... No creo que sea necesario ennumerar todas las razones posibles para apuntalar esta afirmación, pero me gustaría citar a uno de los grandes maestros de la Traductología del siglo XX, Walter Benjamin, que dice:

“... Pues todas las obras literarias conservan su traducción virtual entre líneas, cualquiera que sea su categoría. Pero las Sagradas Escrituras lo hacen en medida muy superior. La versión interlineal de los textos sagrados es la imagen primigenia o ideal de toda traducción".5

\section{El legado árabe y la Europa medieval}

La Europa medieval y, quizás en mayor medida, la renacentista, no hubieran sido lo que fueron de no haber recibido a través de la civilización árabe establecida en Al-Andalus muchas de las obras del pensamiento y la ciencia de la antigüedad clásica ${ }^{6}$. Muy pronto desde su rápida expansión el Imperio Islámico se preocupó por conocer, admirar y asumir todo aquello que los recién dominados pueblos pudieran ofrecerles, que iba desde lo administrativo hasta lo cultural, los conocimientos técnicos, científicos, filosóficos, etc: les llegaban de la India y a través del persa compendios científicos derivados del griego, tratados histórico-mitológicos como los relatos de Kalílah e Dimnah (traducidos al árabe por Ibn Muqaffa' en el s. VIII), pero sobre todo -y a menudo como parte del botín de sus guerras con los bizantinos- las obras filosóficas de la Grecia Clásica.

Fue en la Bagdad del siglo VIII y bajo los auspicios del califa Hārūn al-Rašì (786-809) cuando comenzó a designarse como Jizänat kutub al-hikma (Depósito de los libros de la sabiduría), o simplemente Jizānat al-hikma (Depósito de la sabiduría) lo que más tarde sería conocido por Bayt al-hikma, la Casa de la sabiduría. Bayt al-hikma fue en principio una biblioteca reservada para el uso y disfrute del califa y sus allegados, y las traducciones que en ella se hacían -particularmente de los tratados filosóficos griegos- eran por encargo directo del propio Hārūn al-Rašìd. Sin embargo bajo el califato de su hijo al-Ma'mūn esta actividad traslaticia fue paulatinamente descentralizándose, pues ya no era tan sólo el califa el que ordenaba las traducciones, sino que hombres de Estado y notables de cualquier punto del Imperio Islámico hacían desde la esfera de lo privado sus propios encargos en función de sus intereses particulares: Bayt al-hikma fue el punto de partida de un fenómeno que rápidamente traspasó los límites de una sola institución ${ }^{7}$. A este respecto es interesante resaltar que en una primera etapa muchas de estas versiones árabes no se hicieron

\footnotetext{
${ }^{5}$ W. Benjamin, "La tarea del traductor", Angelus Novus (Barcelona 1970) 127-144

${ }^{6}$ V. García Yebra, En torno a la traducción. Teoría/Crítica/Historia (Madrid 1983)

${ }^{7}$ M.-G. Balty-Guesdon, "Le bayt al-hikma de Bagdad", Arabica XXXIX-2 (1992), 131-150
} 
directamente del griego, sino de traducciones hechas con anterioridad al siríaco o al persa, aunque más tarde se buscarían las obras originales griegas al tomar conciencia de las limitaciones y deficiencias que la doble traducción conllevaba. Por lo que a occidente respecta, es de innegable trascendencia la labor que en Bayt al-hikma se hizo al traducir a Aristóteles, Platón -a través de los neoplatónicos Proclo y Plotino-, ciertas obras de los estoicos, los neopitagóricos y los gnósticos. En medicina se tradujo a Hipócrates y Galeno; en la botánica relacionada con la farmacopea, Dioscórides; de Euclides, Arquímedes y Ptolomeo se tradujeron sus tratados de astronomía, mecánica, geografía, etc ${ }^{8}$. La lista sería interminable.

La mayor parte de esa inmensa labor traductora se transmite a occidente gracias al ambiente de convivencia y tolerancia mutua entre las tres comunidades de creyentes -musulmanes, judíos y cristianos- que moraban en Toledo. La tarea ya se había iniciado bajo el dominio musulmán, pero tras la reconquista de la ciudad por los cristianos no se detuvo, y así a comienzos del siglo XII el arzobispo Raimundo crea una escuela de estudios arábigo-latinos, a la que más tarde el canónigo Gundinsalvo daría un definitivo impulso. La Escuela de Traductores de Toledo se empeña en la tarea de verter al latín las obras griegas que habían llegado a través de al-Andalus y también obras originales del árabe. En su primera etapa la traducción se realizaba de manera oral: usando como lengua intermedia el castellano romance, un judío arabizado -conocedor del árabe y del castellano- leía la obra árabe y en romance se lo transmitía al otro traductor, que lo ponía por escrito en latín. Es de justicia recordar aquí el papel desempeñado por los judíos en la historia de las traducciones en España, no ya en La Escuela de Toledo sino hasta bien entrado el siglo XV, entre ellos Maimónides, quien rechaza la traducción palabra por palabra y defiende la claridad del discurso en la lengua a la que se traduce.

Pero la Escuela de Traductores de Toledo no era la única vía de acceso a la antigüedad clásica (Bassnett-McGuire 1980, 50-51). La traducción del griego al latín se usaba como parte del sistema educativo heredado de los romanos, el trivium y el quadrivium, y a partir del siglo X se traducía no sólo al latín, sino también a las lenguas vernáculas, y lo que es más interesante, de una lengua vernácula a otra. Roger Bacon (1214-1292) y Dante Alighieri (1265-1321) hablan de las cuestiones que la traducción entre lenguas vernáculas plantea, y mientras que el primero hace hincapié; en el problema de la pérdida de sentido o forma, el segundo resalta la importancia de poder acceder a textos de otras lenguas. En cualquier caso, ambos coinciden en señalar que, por una parte, traducir es algo más que un ejercicio de estilística comparada, y por otra, que la precisión del traductor no reside en subordinarse al texto original sino en ser capaz de entender y transmitir lo que en éste se dice, es decir, el sentido. En España, mientras tanto, la lengua castellana romance encuentra un apoyo decisivo para su desarrollo en el impulso que Alfonso X el Sabio, a través de la Escuela de traductores de Toledo, le da a las versiones en lengua vernácula con dos claros

${ }^{8}$ Claude Cahen, El Islam. 1. Desde los orígenes hasta el comienzo del Imperio otomano (Madrid 1986), 117-121 
propósitos, el de ir convirtiendo la lengua romance en una lengua literaria, y en conexión con éste, el de utilizarla como medio de trasmisión didáctica.

\section{Las reflexiones teóricas del Renacimiento}

Una serie de cambios revolucionarios en el ámbito de las ciencias, de la técnica y del conocimiento en general habían transformado la percepción que hasta ese momento el ser humano había tenido de sí mismo. En el mundo de la Letras esa nueva visión queda reflejada en múltiples aspectos, y la traducción no se sustraería a este orden de cosas. Una de las derivaciones fue la reflexión sobre el hecho traductológico de manera sistemática, y uno de estos teóricos fue el francés Etienne Dolet (1509-1546), condenado a la hoguera tras haber traducido "mal" un texto de Platón, de tal manera que se dejaba entrever que el insigne filósofo no creía en la inmortalidad. Pero antes, en 1540, Dolet había escrito un tratado enunciando los principios por los que, según él, se debía guiar un traductor, titulado La manière de bien traduire d'une langue en autre ${ }^{9}$. Estos principios se podrían resumir de la siguiente forma: el traductor

- Debe entender perfectamente el sentido y el significado del texto original.

- Debe tener un perfecto conocimiento tanto de la lengua del original como de la lengua a la que va a traducir.

- No debe traducir palabra por palabra.

- Debe traducir a una lengua común y en uso, sin injerencias de la lengua del texto original, como los calcos latinos.

- Debe mantener la armonía discursiva en el texto traducido.

Como se podrá ver, los principios de Dolet siguen totalmente vigentes, y cualquier traductor actual los suscribiría sin problema alguno. Para Dolet el traductor es algo más que un buen lingüista, es más bien una persona capacitada, por formación académica y por sensibilidad artística, para trasladar de un sistema lingüístico a otro no sólo un texto, sino el alma de ese texto, aprehendida por el traductor y por él plasmada en otro sistema lingüístico y la cultura que éste representa, de la que pasaría a formar parte. Los postulados del francés serían retomados por George Chapman (1559-1634), que en su Epistle to the reader ${ }^{10}$ insertada en su traducción de La Iliada de Homero insiste en que un traductor no debe traducir palabra por palabra ni cargar el texto con erudiciones académicas -lo cual iría en detrimento de la fluidez discursiva-, sino que su misión más clara es la de captar el alma del original y transmitirla.

${ }^{9}$ E. Cary, Les grands traducteurs français (Ginebra 1963), 7-8

${ }^{10}$ G. Chapman, Homer (Londres 1875) 
En España el insigne humanista Juan Luis Vives (1492-1540) expresa sus puntos de vista sobre la traducción en su obra -publicada en 1531-Versiones seu Interpretationes ${ }^{11}$. En ésta se decanta claramente por la traducción del sentido, no de las palabras o de las expresiones idiomáticas, aunque añade que con los textos de los grandes autores Aristóteles, Galeno, etc- se debe tener la habilidad suficiente como para poder expresar en la lengua a la que se traduce, en la medida en que ésta lo admita, la fuerza y la elegancia del estilo del original. Aboga por una traducción libre siempre y cuando el traductor sea fiel a lo que el original quiere transmitir, y añade que una traducción no puede ser fiel si el traductor no conoce bien la lengua del mismo o el tema del que se habla. En esta línea introduce un concepto importante, el del lector, pues para J.L.Vives un traductor ignorante es un traidor a los que confían en él, tanto si la mala transmisión del original ha tenido lugar en el aspecto de la lengua o estilo, como si ha sido en el del contenido. En lo que respecta a éste último, aconseja al traductor que en textos de díficil comprensión -por ejemplo, muchas de las obras de Aristóteles- o en textos de gran importancia pública -las Sagradas Escrituras-, se ciña tanto como pueda al original, pues su interpretación de los pasajes oscuros no se debe interponer entre el lector de la lengua de llegada y el mismo texto original. En el aspecto del estilo o de la lengua, defiende la introducción de neologismos si es moderada y está en consonancia con las costumbres y los hábitos de vida del país. Por otra parte, añade que es aconsejable -si el traductor es lo suficientemente hábil- clarificar y pulir tanto el estilo como la sustancia del original para así ofrecerles a los lectores del texto traducido un mejor producto. Arremete duramente contra aquellos traductores que, llevados "por un sentido de perversa vanidad", desdeñan la concisión y la simplicidad y emplean una innecesaria y engorrosa retórica, incluyendo en el texto palabras que ellos consideran raras, exóticas o arcaicas con la creencia de que así producirán un mejor estilo, cuando en realidad lo que están haciendo es no tomar en consideración la naturaleza y la fuerza del texto en sí.

\section{Siglos XVII y XVIII}

En este siglo los escritores vuelven a retomar como modelo en las artes a los maestros clásicos, y la imitación de los mismos se convierte en el criterio estético de prestigio que se debe seguir, por lo que la traducción de los clásicos aumenta considerablemente, en especial en Francia. Es en este país donde surge la moda de adaptar los textos de tal manera a las costumbres francesas que personajes de la Roma o la Grecia clásicas acaban vistiendo corsé, compran productos de los mercados con francos, o se llaman Michael... Es lo que se ha dado en denominar las belles infidèles. Contra esta manera de traducir escribe Gaspard de Tende (1618-1697) su tratado Règles de la traduction publicado en 1665, en el que expone en nueve reglas muy precisas qué debe y qué no debe hacer un buen traductor. Pone el énfasis en el estilo, la claridad del discurso y el conocimiento de la lengua que se traduce -él habla en concreto de la traducción del latín al francés-, y es en su cuarta regla donde

\footnotetext{
${ }^{11}$ A. Lefevère (ed.), Translation/History/Culture. A Sourcebook (Londres 1992), 50-52
} 
afirma que el traductor debe dejar que los personajes hablen y actúen de acuerdo con su propia naturaleza y costumbres.

En Inglaterra, Sir John Denham (1615-1669) expresa su disconformidad con la traducción literal en la poesía, puesto que es el espíritu de la poesía lo que se debe transmitir, no la lengua (Bassnett-McGuire 1980, 58-59). Considera al autor y a su traductor como artistas del mismo nivel, aunque en contextos sociales y temporales diferentes, por lo que el traductor debe entonces extraer del texto original lo que él perciba que es su esencia y reproducirlo o recrearlo en su propia lengua. En esta misma dirección se movió Abraham Cowley (1618-1667), aunque llevada hasta sus últimas consecuencias. Por su parte, John Dryden (1631-1700) aborda esta cuestión clasificando las posibles maneras de traducir en tres:

- Metalocución, es decir, la traducción palabra por palabra y línea por línea.

- Paralocución, o la traducción del sentido por sentido de Cicerón.

- Imitación, en la cual el traductor se despega del texto original.

Dryden opina que el segundo tipo es el más equilibrado, puesto que de esta manera se tiene en cuenta tanto la forma como el espíritu del autor, y utiliza la metáfora -ya lo habían hecho con anterioridad otros, por ejemplo, G. de Tende- de que el traductor es como un pintor de retratos cuyo deber es que el retrato se parezca al retratado. A esta visión de la traducción se uniría más adelante Alexander Pope (1688-1744)

Por detrás de esta disputa intelectual entre traducción literal $v s$. traducción libre subyace un concepto clave que aparecerá con fuerza en el siglo XVIII, a saber, el deber moral que el traductor tiene contraído para con sus lectores contemporáneos, además del que tiene con el texto original (Bassnett-McGuire 1980, 62-64). En este sentido, Goethe (1749-1832) afirma que la producción literaria de cada lengua debe pasar por tres fases de traducción, que, al ser recurrentes, pueden estar presentes las tres en un mismo sistema lingüístico. En la primera de ellas se entra en contacto con otros países y otras culturas según los modos y maneras del país receptor; en la segunda fase la cultura receptora se apropia del sentido de la obra traducida y lo reproduce a su propia manera; por último, en la tercera fase se produce una perfecta identidad entre el texto original y el texto traducido a través de la creación de una nueva manera de expresión que fusiona la singularidad del original con una forma y estructura distintas. Goethe plantea así un concepto de originalidad de la traducción que bordea la intraducibilidad. 
En 1791 se publicó el primer estudio sistemático en inglés sobre el proceso traslativo, The Principles of Translation, escrito por Alexander Tytler ${ }^{12}$. Los principios básicos -con los queTytler reacciona contra el concepto de paralocución de Dryden- son tres:

- Se debe respetar las ideas del original.

- Se debe respetar el estilo del original.

- Se debe respetar la fluidez del original.

En resumen, se podría afirmar que la teoría de la traducción de los siglos XVII y XVIII se preocupa esencialmente de la dicotomía entre estructura formal y el sentido del alma del original, es decir, en cómo transmitir el alma o espíritu de la obra de arte.

\section{Siglo XIX y primera mitad del XX}

La evolución de la reflexión teórica sobre el hecho traductológico está íntimamente ligada a planteamientos más generales que en cada período histórico recorren y convulsionan las sociedades en las que nacen; planteamientos que pueden ser filosóficos, sociales, culturales, o los relacionados con los descubrimientos técnicos y científicos. En este sentido la concepción romántica del artista, del escritor como Demiurgo de nuevos universos, tendrá consecuencias -a veces paradójicas- en el papel que se le otorga a la traducción y al traductor. El debate fundamental que se plantea es cómo definir la traducción, si como actividad creativa o como labor mecánica. En la primera de ellas se concibe la traducción como una categoría de pensamiento conectada en los sustratos más profundos con la chispa de genio que comparte toda actividad creadora, sea la que sea y provenga de donde provenga, y el traductor es un artista con valor propio que enriquece la literatura y la lengua a la que está traduciendo. Por contra, con la segunda se percibe la actividad traslativa como hecho mecánico que simplemente sirve para dar a conocer un texto o a un autor.

Otra derivación de la concepción del artista como Demiurgo genial de importantes consecuencias para la traducción es la cuestión de la traducibilidad. A menos que el traductor sea él mismo un poeta, ¿cómo va a poder trascender la superficie de la materia escrita y conectar con esa chispa creadora...? La actitud de los propios escritores románticos con respecto a los traductores y a la traducción no deja de ser ambigua: por una parte, hay un casi frenético ir y venir de traducciones, no ya literarias, sino de crítica literaria, estudios filosóficos, etc, que pone en contacto y transmite de un extremo a otro de Europa ese mismo ideal romántico; de otra, lo que ese mismo ideal establece es la supremacía del

12 A. F. Tytler, The Principles of Translation, en Amsterdam Classics in Linguistics vol.13 (Amsterdam 1978) 
genio individual que impregna las palabras y las formas del sentido de lo escrito (BassnettMcGuire 1980, 64-73). De nuevo, se bordea la cuestión de la intraducibilidad.

Las soluciones propuestas por los teóricos decimonónicos son dos:

- El traductor debe concentrarse en la materia escrita del mensaje.

- El uso de una lengua artificial a medio camino entre la del original y la de llegada.

La primera solución conducía inexorablemente a una vuelta al literalismo no sólo lingüístico, sino también histórico, en respuesta a las belles infidèles del siglo anterior; por su parte, la segunda produjo una corriente de traducciones deliberadamente cargadas de arcaismas y. de difícil o casi impenetrable lectura. Con ese extrañamiento lingüístico se pretendía además que el lector se encontrara de lleno inmerso en la sociedad y el momento histórico que produjeron el texto original, que era obviamente distinto al suyo. Uno de los más destacados defensores de esta postura fue Friedrich Schleiermacher (1768-1834), mientras que Dante Gabriel Rossetti (1828-1882) defendía la primera solución y proclamaba la sumisión a la que el traductor debía someterse con respecto a la forma y a la lengua del original.

Pero si el traductor realiza su labor para una minoría de doctos eruditos, los únicos capaces de degustar el sabor de la forma y sentido del texto original a través de una traducción en la que el interés está puesto sólo en ese original, se niega implícitamiente la universalidad del genio creativo en las producciones literarias de todos los tiempos, tal y como defienden los ideales románticos. Por otra parte, si la traducción es usada como un instrumento para mover al lector hacia el texto original y no al contrario, son los propios traductores los que finalmente infravaloran su labor, pues lo que importa no son ni su estilo ni su personal habilidad como escritores, sino simplemente la información que deben transmitir sobre lo que el autor del original dice. La consecuencia última de esta postura fue una generalizada falta de apreciación de la literatura traducida por parte de los lectores, reforzada por la emergencia de los nacionalismos que exaltaban los valores particulares de cada sociedad frente a otras foráneas.

En el extremo opuesto a esta concepción de la traducción se halla el curioso caso de la versión de al-Rubä lyā̄t del autor persa del siglo XII 'Umar al-Jayyām que Edward Fitzgerald (1809-1863) realizó, quien libremente adaptó el original a la lengua y cultura anglosajona de llegada pues lo consideraba de menor valor artístico por proceder de una cultura y una lengua "de menor rango poético". Pero como prueba de la excepcionalidad del caso de Fitzgerald queda la polémica que en su momento hubo en torno a la cuestión de si se trataba de una traducción, una adaptación, una libre versión, etc. De cualquier manera, lo que en el fondo subyace -tanto en el caso de los arcaizantes y literalistas como en el de Fitzgerald- son formas elitistas de concebir la labor traslativa: si en los primeros el elitismo 
reside en el texto y la cultura originales, para el segundo la superioridad está en la cultura y en la producción poética de llegada.

Muchas de estas cuestiones decimonónicas -literalidad, arcaismos, pedantería en la producción de textos traducidos para una minoría, etc- continúan en la primera mitad del siglo XX, y los principales debates teóricos que se plantean son, por una parte, el de la legitimidad de la traducción (traducibilidad $v s$. intraducibilidad) y por otra, la noción de fidelidad en la traducción, con su más evidente consecuencia, la oposición entre traducción literal y traducción libre. Ambos argumentos se implican mutuamente en las reflexiones teóricas que se publican -en general, prólogos a traducciones, crítica de los mismos, etc, con carácter puntual y misceláneo- y en las que se sigue observando la carencia de una sólida base teórica y el predominio de la prescripción sobre la descripción. Autores importantes de esta primera mitad son Walter Benjamin, en la línea de la defensa del literalismo, la misma por la que aboga Ortega y Gasset; Francisco de Ayala, sin embargo, critica tanto la traducción literal como la traducción libre, mientras que V. Larbaud se remite a los postulados de san Jerónimo... ${ }^{13}$

A lo largo de este desarrollo diacrónico que hemos ido exponiendo se habrá podido comprobar que, en realidad, la reflexión teórica sobre la labor traslativa hasta mediados del siglo XX no se sale de los márgenes de las preguntas que en un principio planteamos: por qué, qué, cómo y para quién. En cualquier caso, son las preguntas básicas que todo traductor debe hacerse en el momento de enfrentarse con un texto susceptible de ser traducido... Porque el circulo vicioso en el que indefectiblemente se caía al intentar responderlas no estaba provocado por la pertinencia o no de las preguntas en sí, sino en cómo se respondían: la cuestión de "por qué se traduce" plantea la dicotomía traducibilidad vs. intraducibilidad; la siguiente, es decir, "qué se traduce", gira en torno a la oposición -aún con las posturas intermedias tipo la iusta via media de Vives- traducir la lengua vs. traducir el sentido (el non verbum de verbo, sed sensum exprimere de sensu de Cicerón y Horacio); el "cómo se traduce" se responde de nuevo con una postura irreconciliable, o sea, la traducción literal vs. la traducción libre; por último, la solución a la cuestión "para quién se traduce" ha fluctuado entre tener en consideración al receptor de la traducción, o no tenerlo en absoluto (las elitistas y pedantes traducciones románticas y victorianas)... Está claro que la decisión de elegir una alternativa u otra en cualquiera de las preguntas implicaba necesariamente una correlación con, al menos, la postura que se tomase en el dilema de otra respuesta distinta, es decir, si en el Renacimiento a la cuestión de "qué se traduce" se responde con la opción "traducir el sentido" es porque también se ha tenido en cuenta quién va a ser el receptor del mensaje.

En cualquier caso, el problema de estas reflexiones teóricas es que sistemáticamente conducían a callejones sin salida y a polémicas improductivas que en nada ayudaban al

${ }^{13}$ A. Hurtado Albir, "Perspectivas de los estudios sobre la traducción", Estudis sobre la Traducció (Castellón 1994), $25-38$ 
las posturas irreconciliables), sino también por cuanto el papel del traductor y de la labor traslaticia se ha diversificado enormemente en el dinámico mundo de relaciones internacionales y desarrollo técnico en que vivimos: surgen nuevas variedades de traducción e interpretación -consecutiva, simultánea, automática, etc-, y el campo de acción se abre de forma espectacular, por lo cual se convierte en requisito indispensable la especialización -las ramas jurídicas, científicas, económicas, etc. Por todo ello consideramos que es necesaria una cuidadosa exposición sobre la reflexión teórica de esta segunda mitad del siglo XX, momento en el que, de manera progresiva, las reflexiones sobre la traducción han tomado tales derroteros que, sin duda alguna, podemos hablar de la creación de un nuevo paradigma científico: la Traductología. 
